\title{
Assessment of the Irrigation Capacity during the Dry Season Using Remote Sensing and Geographical Information (Case Study in the Binh Thuan Province, Vietnam)
}

\author{
Hien Thi Thu Le ${ }^{1 *}$, Thang Nguyen Ngoc ${ }^{1}$, Luc Hens ${ }^{2}$ \\ ${ }^{1}$ Institute of Geography, Vietnam Academy of Science and Technology (IG/VAST), Hanoi, Vietnam \\ ${ }^{2}$ Flemish Institute for Technological Research (VITO), Antwerp, Belgium \\ Email: "hientuanphuong@yahoo.com,nnthang0101@yahoo.com, luchens51@gmail.com
}

Received 22 September 2015; accepted 15 November 2015; published 18 November 2015

Copyright (C) 2015 by authors and Scientific Research Publishing Inc.

This work is licensed under the Creative Commons Attribution International License (CC BY).

http://creativecommons.org/licenses/by/4.0/

(c) (i) Open Access

\begin{abstract}
Today satellite system provides a main instrument supplying regular data on land inventory and monitoring of land use/land cover changes, in a timely manner. These data are keys to many applications in different sectors: environment, forestry, hydrology, irrigation, agriculture, geology, resource management and planning. Using Landsat image and change detection, this paper presents a method to extract changes of agricultural land, as the basis for the assessment and development of irrigation systems, which enhance production and protect land resources. During the period 1996-2014, the agricultural land in Binh Thuan decreased from $43.5 \%$ (in 1996) to $40.1 \%$ (February, 2014) of the total land surface in the province. However, the land area under cultivation tends to decrease rapidly, from $25.7 \%$ in 1996 to $14.0 \%$ in 2014 . Combining the results of land use change and assessing the capacity of the irrigation systems show which areas are frequently irrigated versus those are not. This allows proposing irrigation development needs contributing to more production while protecting land resources.
\end{abstract}

\section{Keywords}

Land Use Change, Irrigation, Landsat, Vietnam

\section{Introduction}

Already during the Stockholm Conference on the Human Environment in 1972, "land use and land cover change” ${ }^{*}$ Corresponding author.

How to cite this paper: Le, H.T.T., Ngoc, T.N. and Hens, L. (2015) Assessment of the Irrigation Capacity during the Dry Season Using Remote Sensing and Geographical Information (Case Study in the Binh Thuan Province, Vietnam). International Journal of Geosciences, 6, 1214-1220. http://dx.doi.org/10.4236/ijg.2015.611095 
(LULC) was recognized as a major problem of global environmental change. This was confirmed by the International Conference on Environment and Development (UNCED) in 1992. The International Geospatial and Biosphere Program (IGBP) stimulated research on LULC. The quantification of the location, extent and trend of the change is an important task for scientists. Nowadays, satellite images provide frequent and timely data on land inventories and allow monitoring changes. Long time observations are necessary to establish a database serving the important goals of development trends [1].

Remote sensing data on vegetation, land-use status and its change offer keys for applications in environment, forestry, hydrology, agriculture, and geology. The rationality in natural resource management, planning and monitoring depends on the accuracy and timeliness of the information provided. Methods of monitoring changes in vegetation by remotely sensed data proved the reusefulness and cost-effectivity [2]-[4]. Historical data of LULC changes of the Earth's surface were ultimate importance for any kind of sustainable development programs, including irrigation development. The study of LULC from which solutions for irrigation development orientation were proposed has been carried out since 1970 at different scales: global, regional and local [5].

Local by often, one or more irrigation basins or areas are studied. The limited surface allows investigators to deepen their knowledge of the study sites. As often remote sensing studies demonstrate the application of remote sensing rather than an operational assessment. Moreover, irrigation practices vary with the size of the study area. Consequently methods developed at a particular moment for one place may not be useful for other locations and periods. Two mapping methods that have been widely used in local studies are: visual interpretation and digital image classification. Early work with satellite imagery at the local scale relied on visual interpretation to identify irrigated areas [6] [7]. Landsat images were used drawing the boundaries of irrigated fields by hand. The early visual interpretation of satellite data was later on replaced by integrated automated procedures [8] [9]. These methods used the separation of irrigated fields from harvested and fallow land in the visible and near-infrared portions of the electromagnetic spectrum. Although visual interpretation is still useful, more recent studies focus on digital image classification, of which the analysis time for analysis is shorter and the mapping costs are lower. Multi-stage classification, unsupervised clustering and decision tree classification are widely used in this context.

Binh Thuan is a province of the South Central Coast of Vietnam. It stretches from $10^{\circ} 33^{\prime} 42^{\prime \prime}$ to $11^{\circ} 33^{\prime} 18^{\prime \prime}$ north, and from $107^{\circ} 23^{\prime} 41^{\prime \prime}$ to $108^{\circ} 52^{\prime} 42 "$ east. The province covers 781.282 ha, including $40.06 \%$ agricultural land, $46.10 \%$ forested land, and $10.08 \%$ non-agricultural land, while other uses apply to the rest of the land [10]. However, in reality, the land area used for agricultural production during the dry season is limited as a result of water shortage. In particular these lands are prone to degradation and desertification. Therefore, these regions need to be monitored and appropriate measures for the reuse and protection are imperative.

This article presents an approach using Landsat imagery to assess the land use change. The focus is on practical aspects of farming during the dry season, assessing the hydraulic capacity, inducting how irrigation system should be developed, enhancing and protecting the arable land.

\section{Materials and Methodology}

\subsection{Satellite Data}

Satellite images allow a fast and reliable review of the vegetation and the basic land characteristics. They equally allow repetitive direct observation of the surface, mapping and monitoring surface objects and monitoring, and assessing changes over time and space. Landsat images with a ground resolution of $30 \mathrm{~m} \times 30 \mathrm{~m}$, allow mapping at large and medium scale. An image Database has been built since 1972 (up to present) is now freely accessible in the US Geological Survey (USGS) store, the images are suitable for LULC research and monitoring. For this work, remotely sensed data of the Binh Thuan province were downloaded from USGS indicated in Table 1 [11].

Determining whether the agricultural land is cultivated or not during the dry season in the Binh Thuan province. Using Landsat images captured during the dry season (January to April are the months of dry season). The images are spread over: 1996; 2001; 2005; 2010 and 2014. 1996 is the first year providing good quality data; 2005 and 2010 are important milestones in orienting and planning the country's development, and 2014 is the most recent year under study.

\subsection{Image Classification}

The maximum likelihood is the algorithm used for supervised classification is. The sample selection was carried 
out using a histogram in combination with field sampling of all types of land use: cultivated agricultural land; non-cultivated agricultural land; dense forest; seasonal forest; sparse forest, shrub, settlement, fallow land; water surfaces. The reflectance characteristics and digital number values on Landsat data, agricultural land is hard to recognize, cultivated agricultural land is often confused with sparse forest, or shrub; agricultural area (nonvegetation) with dry soil is often confused with fallow land. Therefore, it is necessary to use ancillary data: field surveys complete the current land use map.

To monitor the change in land use, this paper applies detection method with separately-classified images [12]. The flowchart of processing Landsat images to monitor agricultural area changes are shown in Figure 1. Landsat images have been calibrated, enhanced and classified independently. Land use changes were used in pair analysis between the years: 1996-2001; 2001-2005; 2005-2010 and 2010-2014. The long and continuous observation period allows identifying the cultivated and non-cultivated agricultural area, this further provide basis for proper use of resources and irrigation development.

The classification results were assessed using the Kappa coefficient: Kappa allows assessing the accuracy of the classification based on a random method [13].

Table 1. Landsat data of Binh Thuan province from 1996-2014.

\begin{tabular}{cccccccc}
\hline No & Satellite & Path/row & Date & No & Satellite & Path/row & Date \\
\hline 1. & Landsat-5 & $123-52$ & $23 / 2 / 1996$ & 9 & Landsat-7 & $124-53$ & $3 / 4 / 2005$ \\
2. & Landsat-5 & $124-52$ & $1 / 3 / 1996$ & 10 & Landsat-7 & $124-52$ & $5 / 2 / 2010$ \\
3. & Landsat-5 & $124-53$ & $1 / 3 / 1996$ & 11 & Landsat-7 & $124-52$ & $12 / 2 / 2010$ \\
4. & Landsat-7 & $123-52$ & $17 / 4 / 2001$ & 12 & Landsat-7 & $124-53$ & $16 / 3 / 2010$ \\
5 & Landsat-7 & $124-52$ & $8 / 4 / 2001$ & 13 & Landsat-8 & $123-52$ & $23 / 1 / 2014$ \\
6 & Landsat-7 & $124-53$ & $8 / 4 / 2001$ & 14 & Landsat-8 & $124-52$ & $15 / 2 / 2014$ \\
7 & Landsat-7 & $124-52$ & $11 / 3 / 2005$ & 15 & Landsat-8 & $124-53$ & $15 / 2 / 2014$ \\
8 & Landsat-7 & $124-52$ & $2 / 3 / 2005$ & & & & \\
\hline
\end{tabular}

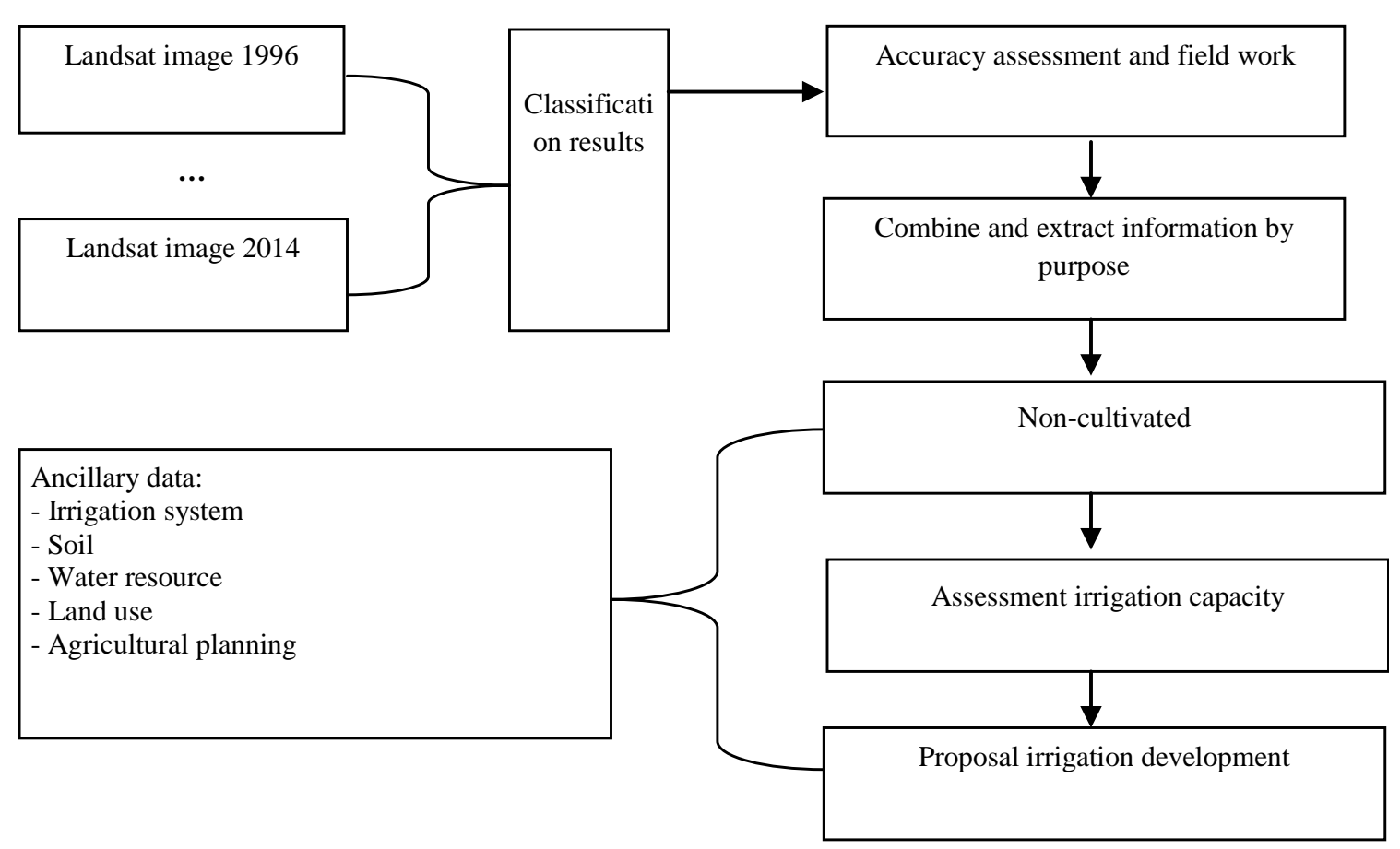

Figure 1. Flowchart of the study rationale: processing data analysis and proposal of irrigation development. 


$$
\text { Kappa }=\text { A } / B
$$

$A=$ correct by classified pixels - errorously classified pixels.

$B=$ total number of classified pixels.

Kappa is a measure of this difference, standardized to lie on a -1 to 1 scale, where 1 is perfect agreement; 0.81 - 0.99: almost perfect; 0.61 - 0.80: substantial; 0.41 - 0.6 moderate; 0.21 - 0.40: fair; $0.01-0.20$ : slight; 0 is poor agreement; and $<0$ less than chance agreement [14].

Pixels are selected based on a random method, verified using land use map combined with field observations The accuracy assessment of the classification results are presented in Table 2.

Table 2 shows the accuracy of image interpretation results for land use in the study area. All the Kappa coefficients ranging from 0.73 to 0.93 ; so the results are interpreted on the substantial or almost perfect agreements.

\subsection{Assessment of the Irrigation Capacity}

Agricultural production is influenced by many factors, but the supply of water or irrigation capacity is the important one. This study approach towards evaluated the capacity of the irrigation system using of satellite images.

Satellite image interpretation is one of the methods establishing the capacity of the irrigation system. The approach is supported by data on spatial distribution of the reservoir; dams; canals; the pumping station; and the irrigated area.

Classification results from 1996-2014 show the distribution of unused agricultural land (non-planted during the dry season). Analysis and comparison of the irrigated and non-irrigated areas reveal the capacity of the irrigation system.

The following analytical methods were used: density; statistical and comparison methods.

\section{Results and Discussion}

\subsection{Change in Cultivated Agricultural Land during the Period 1996-2014}

$89 \%$ of the land in Binh Thuan is used for agriculture: $40 \%$ of that area is for annual cropping. The analysis of land use change using satellite data showed minimal changes in this areas coved (annual crops): from $43 \%$ (in 1996) to 40\% (in 2014) (Table 3). In contrast "specialized" land (homestead, industrial land, transportation land) more often changes use. This corresponds with other result on land use and land cover change in Binh Thuan Province [15].

However, a major concern is that the surface of land cultivated during the dry season only accounts for a small portion and is significantly decline. In other words: the agricultural area that is left unused during the dry season is increases (Figure 2 and Table 3). These results were the same as the data collected from field trip by local agencies [16]. This is explained by the change in the climate: the weather becomes more extreme during the dry season and the current irrigation capability can not meet the production demand.

Meteorological data show the change in precipitation in the region: the amount of rainfall reduces during the dry season and increased during the rainy season. Climate change and drought scenarios for the periods 2015-2100 forecast that the even suffering from severe drought will expand to the North and the East of the province, occupying the entire Phan Thiet city and half of the districts Bac Binh, Tuy Phong, Ham Thuan Bac and Ham Thuan Nam [17]. Water shortage is becoming more and more severe in these areas.

Table 2. Accuracy assessment of the classification results using the Kappa coefficient.

\begin{tabular}{|c|c|c|c|c|c|}
\hline \multirow{2}{*}{ Land use type } & \multicolumn{5}{|l|}{ Year } \\
\hline & 1996 & 2001 & 2005 & 2010 & 2014 \\
\hline Cultivated land & 0.73 & 0.88 & 0.89 & 0.91 & 0.81 \\
\hline Non-cultivated land & 0.88 & 0.93 & 0.74 & 0.85 & 0.88 \\
\hline Others & 0.80 & 0.89 & 0.83 & 0.87 & 0.86 \\
\hline Average Kappa coefficient & 0.80 & 0.86 & 0.86 & 0.85 & 0.88 \\
\hline
\end{tabular}




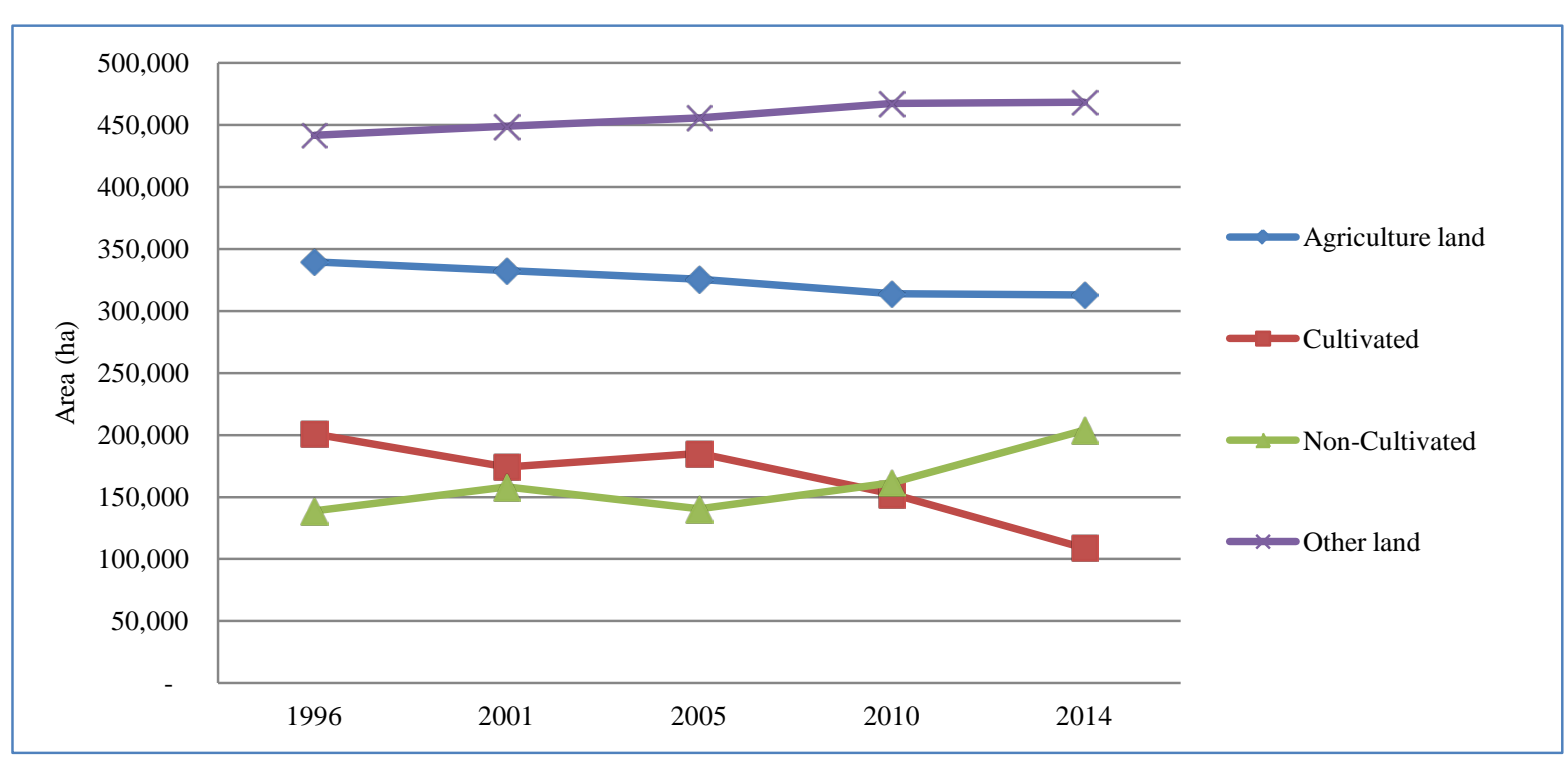

Figure 2. Land use change in Binh Thuan during the period 1996-2014.

Table 3. Change in agricultural area in dry season during the period 1996-2014.

\begin{tabular}{lccccccccccc}
\hline \multirow{2}{*}{ Land use types } & \multicolumn{3}{c}{ Year 1996 } & \multicolumn{2}{c}{ Year 2001 } & \multicolumn{2}{c}{ Year 2005 } & \multicolumn{2}{c}{ Year 2010 } & \multicolumn{2}{c}{ Year 2014 } \\
\cline { 2 - 12 } & Area (ha) & $\%$ & Area(ha) & $\%$ & Area(ha) & $\%$ & Area(ha) & $\%$ & Area(ha) & $\%$ \\
\hline \multirow{2}{*}{ Agricultural land: } & 339,582 & 43.5 & 332,426 & 42.5 & 325,593 & 41.7 & 314,023 & 40.2 & 312,967 & 40.1 \\
-Cultivated & 200,880 & 25.7 & 174,287 & 22.3 & 185,153 & 23.7 & 152,495 & 19.5 & 108,997 & 14.0 \\
-Non-cultivated & 138,701 & 17.8 & 158,139 & 20.2 & 140,439 & 18.0 & 161,528 & 20.7 & 203,970 & 26.1 \\
Others & 441,701 & 56.5 & 448,857 & 57.5 & 455,690 & 58.3 & 467,260 & 59.8 & 468,315 & 59.9 \\
\hline
\end{tabular}

The fast development of the irrigation capacity in Binh Thuan over the past 10 years, shows that lakes have been built, while the canal system is still limited. Consequently even when sufficient amounts of water are available in the lakes, the crops are still suffering drought.

\subsection{Irrigation Capacity}

Table 4 shows the area of agricultural land is cultivated frequently during the dry season in both areas (have irrigation systems and non-irrigation) which accounts for a very small areas (here taken as the high number of cultivate times in 5 years study from 1996-2014). And the large of the agricultural land areas are unstable cultivated and quite big of the agricultural land areas has not been cultivated in a long time. This suggests that irrigation systems perform poorly during the dry season.

Figure 3 shows 3 areas which are still cultivated during the dry season: the Luy River Basin (Tuy Phong district); the Quao River Basin (located in Ham Thuan Bac) and the La Nga River Basin (Tanh Linh district). These areas are intensively cultivated which is possible because of the dams; and pumping stations.

\subsection{Irrigation Development}

Developing a more comprehensive irrigation system should be based on the combined results of change detection analysis and the assessment irrigation capacity. Change detection analysis shows that the status of agricultural land and irrigation of Binh Thuan during the dry season, is different for: 1) without irrigation; 2) unstable irrigation (occasional watering); 3) and stable irrigation (frequent watering). This allows proposing different amounts of irrigation water demand, both to secure the irrigation sources for the crops and to maintain soil moisture, preventing the soil from degradation. Details entail: 
Table 4. Cultivated areas in the dry season during period 1996-2014.

\begin{tabular}{ccccc}
\hline \multirow{2}{*}{$\begin{array}{c}\text { The number of } \\
\text { cultivated times }\end{array}$} & \multicolumn{2}{c}{ In areas with built irrigation } & \multicolumn{2}{c}{ In areas without built irrigation } \\
\cline { 2 - 5 } 1 & Ha & \% of the total agriculture land in 2014 & Ha & \% of the total agriculture land in 2014 \\
2 & $39,553.65$ & 0.13 & $87,382.2$ & 0.37 \\
3 & $37,823.40$ & 0.12 & $45,168.1$ & 0.14 \\
4 & $24,364.26$ & 0.08 & $18,039.2$ & 0.06 \\
5 & $13,490.19$ & 0.04 & $4,549.0$ & 0.01 \\
Total & $5,199.84$ & 0.02 & $269,446.6$ & 0.86 \\
\hline
\end{tabular}

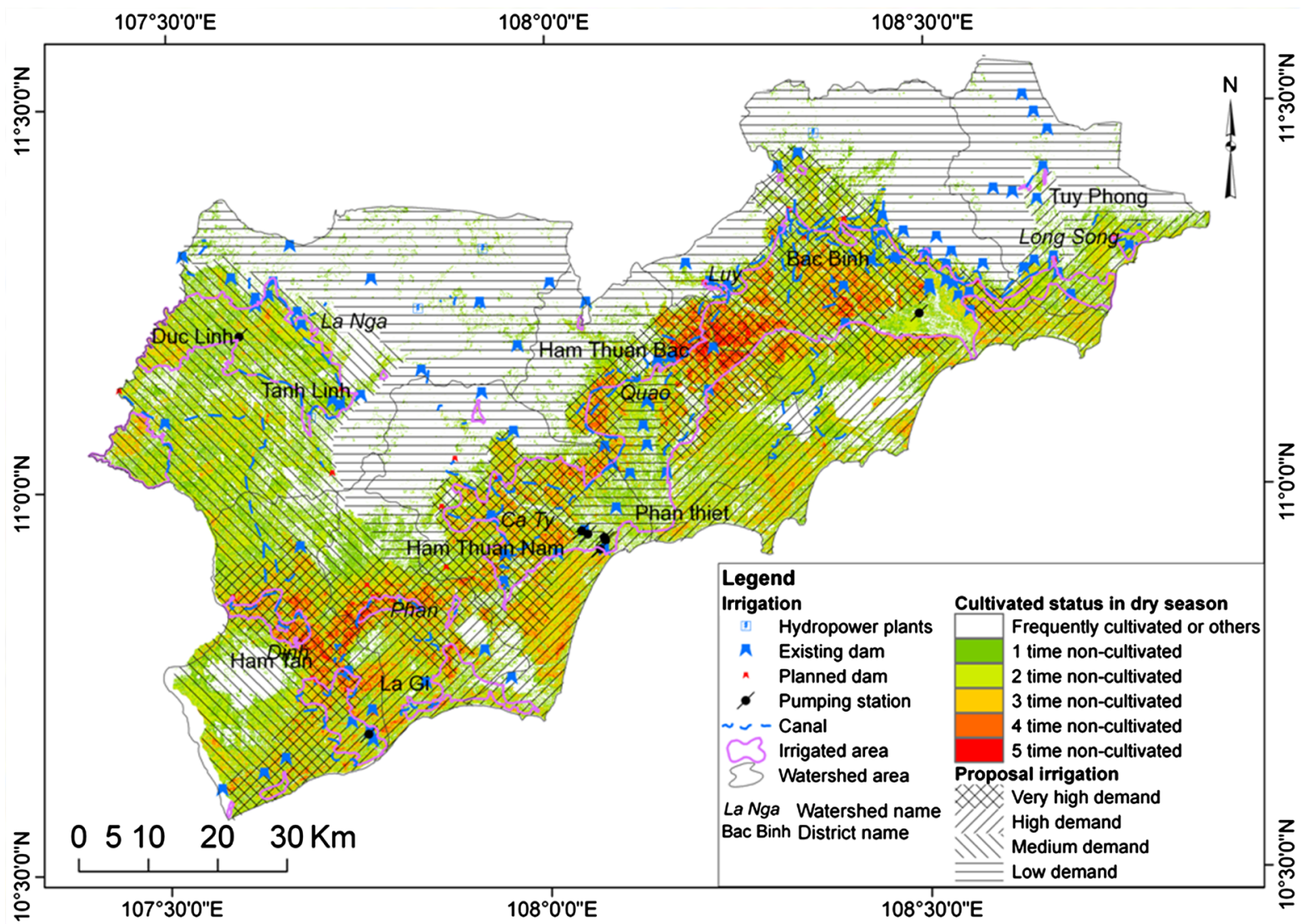

Figure 3. Current agricultural land use status and irrigation.

- Areas for agricultural production are often not cultivated during the dry season (in the period 1996-2014) due to the lack of irrigation in the foothill plains of the Bac Binh, Ham Thuan Bac, Ham Thuan Nam and Ham Tan districts. These areas are during the dry season, are often rarely used, dry and consequently shows signs of degradation. This region needs to be equipped with irrigation systems to improve the soil moisture during the dry season, and to reduce the risk of degradation. The need for an irrigation system is very high in these districts.

- Agricultural land is not cultivated all over the dry season as a result of unreliable irrigation water distribution mainly from Tuy Phong to Ham Tam. Here sandy soils dominate huge sand dunes and poor agricultural situations. In many places, sand encroaches the fields. These areas are in a high need of irrigation and protective forest to combat desertification.

- The agricultural land which already has stable irrigation (in Duc Linh, Tanh Linh and some other parts of Ham Thuan Bac and Bac Binh) should have an irrigation system at medium level. 


\section{Conclusions}

Landsat satellite images allow analyzing land use changes at large and medium scale. The analysis locates and quantifies the area of change, and identifies the change of land use over time. The method provides recent data and allows updated and cost-effective assessments.

The agricultural land in Binh Thuan has declined in a limited way, from $43 \%$ (in 1996) to $40 \%$ (in 2014). But the area of agricultural land during the dry season only accounts for a small fraction and significantly decreases. This is related to changes in the weather and an insufficient irrigation system.

Combining land use changes and the irrigation system assessment, allows recommending for the region: frequently irrigated or non-irrigated areas, as the basis of an irrigation system providing sufficient water, fulfill the needs for production and land resource protection.

\section{Acknowledgements}

This work was a part of the research project code VAST.DLT 13/13-14 and funded by Vietnam Academy of Science and Technology (VAST).

\section{References}

[1] NASA (2014) Land Cover/Land Use Change Program. http://lcluc.umd.edu/program_information.php?tab=1

[2] Prakasam, C. (2010) Land Use and Land Cover Change Detection through Remote Sensing Approach: A Case Study of Kodaikanal Taluk, Tamil Nadu. International Journal of Geomatics and Geosciences, 1, 150-158.

[3] Ryngnga, P.K., Bring, B. and Ryntathiang, L. (2013) Dynamics of Land Use Land Cover for Sustainability: A Case of Shillong, Meghalaya. International Journal of Scientific \& Technology Research, 2, 235-239.

[4] SIC (2014) Satellite Imagery and GIS for Land Cover and Change Detection. http://www.satimagingcorp.com/applications/environmental-impact-studies/land_cover_and_change_detection/

[5] Ozdogan, M., Yang, Y., Allez, G. and Cervantes, C. (2010) Remote Sensing of Irrigated Agriculture: Opportunities and Challenges. Remote Sensing, 2, 2274-2304. http://dx.doi.org/10.3390/rs2092274

[6] Robert, C.N. (1997) An Inventory of Irrigated Lands for Selected Counties within the State of California Based on LANDSAT and Supporting Aircraft Data. University of California, Berkeley, Space Sciences Laboratory. http://ntrs.nasa.gov/archive/nasa/casi.ntrs.nasa.gov/19770024625.pdf

[7] Heller, R.C. and Johnson, K.A. (1979) Estimating Irrigated Land Acreage from Landsat Imagery. Photogrammetric Engineering \& Remote Sensing, 45, 1379-1386.

[8] Haack, B., Wolf, J. and English, R. (1998) Remote Sensing Change Detection of Irrigated Agriculture in Afghanistan. Geocarto International, 13, 65-75. http://dx.doi.org/10.1080/10106049809354643

[9] Thiruvengadachari, S. (1981) Satellite Sensing of Irrigation Patterns in Semiarid Areas: An Indian Study [Tamil Nadu State, India]. Journal of Photogrammetric Engineering and Remote Sensing, 47, 1493-1499.

[10] Binh Thuan Statistical Office (2014) Statistical Yearbook Binh Thuan Province. http://cucthongke.vn/ngtk/ngtk2013/index.html\#/8

[11] USGS (2014) Earth Explorer. http://earthexplorer.usgs.gov/

[12] Mas, J.F. (1999) Monitoring Land-Cover Changes: A Comparison of Change Detection Techniques. International Journal of Remote Sensing, 20, 139-152. http://dx.doi.org/10.1080/014311699213659

[13] Congalton, R.G. (1991) A Review of Assessing the Accuracy of Classifications of Remotely Sensed Data. Remote Sensing of Environment, 37, 35-46. http://dx.doi.org/10.1016/0034-4257(91)90048-B

[14] Viera, A.J. and Garrett, J.M. (2005) Understanding Interobserver Agreement: The Kappa Statistic. Family Medicine, 37, 360-363.

[15] Hountondji, Y. and Ozer, P. (2011) Land Use and Land Cover Change Analysis 1990-2002 in Binh Thuan Province, South Central Vietnam. 1st International Conference on Energy, Environment and Climate Change.

[16] Binh Thuan Province’s Committee (2005) Report on Drought and Others Remedial Measure to Support Farming. Department of Agriculture and Rural Development, Binh Thuan.

[17] Huong, P.T.T. (2010) Scenarios of Climate Change and Drought in Binh Thuan Province. Report on the Project: Research on the Effects of Climate Change and Desertification South Central Region (Pilot Study Binh Thuan Province), Institute of Geography (VAST), Vietnam. 